\title{
O uso dos conceitos de ocupaçáo e atividade na Terapia Ocupacional: uma revisão sistemática da literatura ${ }^{1}$
}

\author{
Mariana Moraes Salles, Thelma Simóes Matsukura \\ Departamento de Terapia Ocupacional, Universidade Federal de São Carlos - UFSCar, São Carlos, SP, Brasil.
}

\begin{abstract}
Resumo: Introdução: Os conceitos de ocupação e atividade são conceitos centrais para a Terapia Ocupacional, e vêm sendo utilizados diversamente ao longo do tempo, conforme o país, a cultura e o período histórico. Objetivo: O presente estudo tem como objetivo contribuir para o conhecimento do uso dos conceitos de atividade e ocupação na Terapia Ocupacional, na literatura internacional e nacional. Método: Foi realizada uma revisão sistemática de literatura sobre o tema. Resultados: A pesquisa na literatura explorou artigos completos publicados entre 2003 e 2013, totalizando 19 artigos incluídos nesta pesquisa. Os textos relatam a importância de um uso adequado das terminologias na Terapia Ocupacional, como um meio para fortalecer a profissão e promover a coerência nas pesquisas e na prática da Terapia Ocupacional. São descritas algumas das diferenças e semelhanças na utilização dos termos atividade e ocupação na literatura nacional e internacional. Verificou-se que tanto o termo atividade como o termo ocupação se referem a um fazer que é capaz de influenciar os processos de saúde e doença. Conclusão: A conceituação sobre os termos ocupação e atividade estão em processo de construção histórica, e serão necessárias mais pesquisas sobre o assunto para aprofundar o conhecimento sobre o tema.
\end{abstract}

Palavras-chave: Terapia Ocupacional, Literatura de Revisão como Assunto, Formação de Conceito.

\section{The use of occupation and activity concepts in Occupational Therapy: a systematic literature review}

\begin{abstract}
Introduction: The occupation and activity concepts are central for Occupational Therapy, and have been used diversely over time according to the country, culture and historical time. Objective: This study aims at contributing to the knowledge on the use of occupation and activity concepts in Occupational Therapy in the national and international literature. Method: We conducted a systematic literature review on the subject. Results: The literature research explored full articles published between 2003 and 2013, in total 19 articles were included in this study. The texts report the importance of the adequate use of terminologies in occupational therapy as a means to strengthen the profession, and promote the coherence in the Occupational Therapy research and practice. A few differences and similarities in the use of the terms activity and occupation in the national and international literature are described. We noticed that the term activity as the term occupation both refer to a practice that is able to influence the health and illness process. Conclusion: The concepts of occupation and activity are historically developing, and more research about that matter is necessary to deepen the knowledge in this subject.
\end{abstract}

Keywords: Occupational Therapy, Review Literature as Topic, Concept Formation.

\footnotetext{
Autor para correspondência: Thelma Simões Matsukura, Programa de Pós-graduação em Terapia Ocupacional, Centro de Ciências Biológica e da Saúde, Universidade Federal de São Carlos, Rodovia Washington Luiz, Km 235, Monjolinho, CEP 13565-905, São Carlos, SP, Brasil, e-mail: marianamsalles@gmail.com
}

Recebido em Jan. 23, 2015; $1^{\text {a }}$ Revisão em Abr. 23, 2015; 2a Revisão em Ago. 19, 2015; Aceito em Dez. $20,2015$. 


\section{Introdução}

Os conceitos de ocupação e atividade são conceitos centrais para a Terapia Ocupacional e vêm sendo utilizados ao longo do tempo e se ressignificando conforme o país, a cultura e o período histórico. Neste processo, diferentes países seguiram caminhos próprios, que conduziram a distintas utilizaçôes conceituais destes termos.

Desde o início da profissão, a sociedade ocidental já tinha conhecimentos sobre formas apropriadas de viver e uma parte importante desta forma saudável de viver era expressa através da ocupação (KANTARTZIS; MOLINEUX, 2011). Nesta direção, Ivarsson e Müllersdorf (2008) apontam que um dos objetivos da pesquisa em Terapia Ocupacional é descobrir a relação entre ocupação humana e saúde, que é um pressuposto central da profissão.

Como observou Pierce (2003, p. 13),

[...] ocupaçấo e atividade são dois conceitos centrais em Terapia Ocupacional, porém seus significados têm permanecido entrelaçados desde o começo da profissão.

Nos últimos anos, os termos ocupação e atividade têm sido teorizados entre os terapeutas ocupacionais; algumas vezes, esses termos são usados intercambiavelmente e nem sempre há consistência na maneira como eles são usados (MÜLLERSDORF; IVARSSON, 2008). O uso terapêutico da ocupação e da atividade é considerado como um elemento único e central da prática profissional da Terapia Ocupacional. Porém, ainda existem confusóes sobre como estes termos são usados (GOLLEDGE, 1998).

Ao traduzir conceitos, modelos e avaliaçóes desenvolvidas nos países ocidentais para línguas diferentes do inglês, percebe-se que estas questóes são mais complexas do que a simples tradução da linguagem. Neste sentido, é importante refletir criticamente sobre os diferentes embasamentos culturais que sustentam a evolução do conceito de ocupação (RUDMAN; DENNHARDT, 2008).

O Brasil tem um longo histórico no desenvolvimento do conceito de atividade (LIMA; PASTORE; OKUMA, 2011) e, mais recentemente, passou a se debruçar também sobre a conceituação do termo ocupação, conforme desenvolvido pelos países ocidentais (MAGALHÁES, 2013).

O presente estudo tem como objetivo contribuir para o conhecimento do uso dos conceitos de atividade e ocupação na Terapia Ocupacional, na literatura de língua inglesa e brasileira. Assim, a questão norteadora para pesquisa foi: Como têm sido definidos e usados os conceitos de ocupação e atividade na área de conhecimento e atuação da Terapia Ocupacional nos últimos anos?

\section{Método}

Foi realizada uma revisão sistemática sobre o tema. A revisão sistemática avalia e sintetiza os resultados das pesquisas encontradas na literatura, procurando mapear todo o conhecimento existente sobre um tópico.

A revisão sistemática foi desenvolvida seguindo as etapas de construção de um protocolo, com definição da pergunta que guia a pesquisa, busca dos estudos, seleção dos estudos, avaliação crítica dos estudos, coleta de dados e síntese dos dados (GALVÃO; SAWADA; TREVIZAN, 2004).

Recentemente, as revisóes sistemáticas se ampliaram e foram incorporados náo apenas os estudos com metodologias quantitativas, mas também estudos qualitativos ou com metodologia mista, na abrangência das pesquisas analisadas (GRANT; BOOTH, 2009).

A pesquisa na literatura internacional explorou artigos completos publicados nos últimos dez anos (2003 a 2013), em periódicos revisados por pares, nos idiomas inglês e português, indexados no Portal de Periódicos CAPES e que investigaram ou abordaram o uso dos conceitos de ocupação e atividade na área de conhecimento e atuação da Terapia Ocupacional. O Portal de Periódicos CAPES é uma biblioteca virtual que reúne e disponibiliza uma parcela significativa da produção científica internacional.

Foram utilizadas as palavras-chave no título: occupational therapy and activity e occupational therapy and occupation. Os estudos foram selecionados através do título e da leitura dos resumos, segundo os seguintes critérios de inclusão: estudos quantitativos e qualitativos; estudos de revisão bibliográfica; estudos referentes a todas as áreas de atuação na Terapia Ocupacional, e sem limitaçóes em relação à idade da população estudada. Foram excluídos trabalhos que não eram referentes ao tema proposto, ou seja, que não utilizavam ou não faziam referência aos conceitos de atividade ou de ocupação. Também não foram utilizados editoriais, cartas, trabalhos publicados apenas na forma de resumos ou artigos que não possuíam o acesso ao texto completo.

Como a pesquisa das palavras-chave: terapia ocupacional e atividade, e terapia ocupacional e ocupação, versão em português da pesquisa realizada em inglês não obteve resultados significativos junto ao Portal CAPES, decidiu-se por proceder à pesquisa 
na bibliografia nacional, a partir dos periódicos nacionais, um a um.

Os periódicos incluídos na pesquisa foram: Revista de Terapia Ocupacional da Universidade de São Paulo, Cadernos de Terapia Ocupacional da UFSCar, Revista do Centro de Estudos de Terapia Ocupacional (CETO), Revista Baiana de Terapia Ocupacional e Cadernos de Terapia Ocupacional do GES.TO (Grupo de Estudos Profundos de Terapia Ocupacional). Seguiram-se os mesmo critérios de inclusão/exclusão utilizados para a literatura internacional.

Utilizou-se uma planilha para organização dos estudos localizados conforme título, autor, ano, local de produção do artigo, revista em que o artigo foi publicado, metodologia, tema e faixa etária da populaçáo do estudo.

A busca com os termos em inglês occupational therapy and occupation resultou em 227 artigos, e a busca com os termos occupational therapy and activity resultou em 145 artigos, tendo sido selecionados para análise aqueles que tratavam especificamente da terminologia ou da definiçáo dos conceitos de ocupação e atividades, ou seja, foram selecionados 12 estudos da literatura de língua inglesa (BAUERSCHMIDT; NELSON, 2011; CREEK; HUGHES, 2008; HAMMELL, 2009; HOCKING, 2013; IVARSSON; MÜLLERSDORF, 2008, 2009; KANTARTZIS; MOLINEUX, 2011; MÜLLERSDORF; IVARSSON, 2008; LARSON, 2004; MOLKE; RUDMAN, 2009;
REED; HOCKING; SMYTHE, 2013; RUDMAN; DENNHARDT, 2008).

Como resultado da busca na literatura nacional, foram identificados sete artigos nacionais: três artigos dos Cadernos de Terapia Ocupacional da UFSCar, três artigos da Revista do Centro de Estudos de Terapia Ocupacional e um da Revista de Terapia Ocupacional da Universidade de Sáo Paulo (BENETTON, 2008; LIMA; PASTORE; OKUMA, 2011, 2013; MAGALHÁES, 2013; MORAES, 2008; PIERCE, 2003; SILVA, 2013). Nenhum artigo foi incluído da Revista Baiana de Terapia Ocupacional ou dos Cadernos de Terapia Ocupacional do GES.TO.

Assim, totalizaram-se 19 artigos, publicados nos últimos dez anos, que apresentaram como escopo conceituar e definir os termos ocupação e atividade, conforme indicado na Figura 1, fluxograma da seleção das referências.

\section{Resultados e Discussão}

Parte dos artigos relata a importância de um uso adequado das terminologias na Terapia Ocupacional, como um meio para fortalecer a profissão e promover a coerência nas pesquisas e na prática da Terapia Ocupacional (BAUERSCHMIDT; NELSON, 2011; MÜLLERSDORF; IVARSSON, 2008; MAGALHÃES, 2013; PIERCE, 2003; LIMA; PASTORE; OKUMA, 2011).

As palavras usadas por uma determinada organização ou disciplina, em um determinado

372 artigos internacionais localizados

\begin{tabular}{|l|l|}
\hline$\downarrow$ & $\begin{array}{l}\text { Excluídos artigos repetidos, resenhas de livros, } \\
\text { apresentações de congresso, comentários, pontos de vista, } \\
\text { editoriais e carta ao editor, e artigos que não eram } \\
\text { pertinentes ao tema. }\end{array}$ \\
\hline
\end{tabular}

144 artigos internacionais e 12 artigos nacionais encontrados sobre o tema

Seleção dos artigos que tratavam especificamente da terminologia ou da definição dos conceitos de ocupação e atividade.

12 estudos da literatura internacional e 7 na literatura nacional selecionados

Figura 1. Fluxograma da seleção das referências. 
momento, refletem a visão de mundo comum de seus participantes (BAUERSCHMIDT; NELSON, 2011). Além disso, a maneira como os conceitos são construídos influencia a forma como os terapeutas ocupacionais desenvolvem serviços e formulam questóes de pesquisa (RUDMAN; DENNHARDT, 2008).

Porém, como um dilema antigo da Terapia Ocupacional, existe a falta de clareza e coesáo em o que constitui o conceito de ocupação na nossa sociedade (CREEK; HUGHES, 2008). Além disso, os termos ocupação e atividade variam de autor para autor e, algumas vezes, variam dentro de um mesmo trabalho (BAUERSCHMIDT; NELSON, 2011). Além disso, o uso destes termos varia de país para país, da mesma forma em que há temas em comum entre as diferentes linguagens e países (NELSON; JONSSON, 1999).

Pierce (2003, p. 13) observa que a falta de diferenciação entre estes conceitos "[...] impede a pesquisa, reduz a confiança e a efetividade dos profissionais, e abafa a voz política da profissão".

Na mesma perspectiva, autores brasileiros (LIMA; PASTORE; OKUMA, 2011, p. 69) apontam que

[...] a diversidade das experiências em TO, sem uma clareza de suas diferenças conceituais, e o uso dos diferentes termos sem uma explicitaçáo de sua compreensão, dificultam a descriminação de diferentes perspectivas teóricas no interior da área.

Não obstante, a definição e a utilização destes termos refletem a forma de pensar da própria Terapia Ocupacional. Os termos ocupação e atividade estáo presentes desde a origem da Terapia Ocupacional e são os conceitos primordiais, que promoveram o desenvolvimento da profissão.

O termo ocupação está arquivado na literatura pelos fundadores da Terapia Ocupacional: o propósito da nova profissão era avançar na ocupação como uma medida terapêutica. A ocupação foi descrita como tão necessária para a vida como a comida ou a bebida. Considerava-se que mentes ou corpos doentes poderiam ser curados pela ocupação (BAUERSCHMIDT; NELSON, 2011).

O termo atividade também tem tido uma ressonância histórica na profissão. De acordo com Bauerschmidt e Nelson (2011), Slagle usava o termo análise ocupacional, porém Fidler, nos seus primeiros escritos, se refere à análise da atividade e, mais tarde, ela usa o termo ocupação como alternativa para atividade. Em resumo, as evidências sugerem que existe uma transformação no uso dos termos ocupaçâo e atividade ao longo do tempo, na história da Terapia Ocupacional.

Apesar de todas as diferenças na construção histórica dos termos, de forma geral, na literatura de língua inglesa, parece haver o enfoque do termo ocupação como o utilizado na origem da profissão, porém este fato não ocorre na literatura nacional. Assim, percebe-se o lugar central que estes termos assumiram no desenvolvimento da Terapia Ocupacional, norteando os caminhos a serem trilhados pela profissão. Lima, Okuma e Pastore (2013, p. 244) apontam que "[...] atividades, ações e ocupaçóes figuram o centro da busca de definição teórica da Terapia Ocupacional”.

Além disso, cada país tem o seu próprio processo histórico, desenvolvimento e uso dos termos em seu contexto social, e sua linguagem, que levam a diferentes formas de compreender os conceitos centrais relacionados à profissão (NELSON; JONSSON, 1999).

\subsection{O uso do termo atividade no Brasil}

Apesar da plurivocidade dos termos, na Terapia Ocupacional brasileira, a partir de certo momento do desenvolvimento da profissão, o conceito de atividade se universalizou, abarcando questóes relativas ao cotidiano [e às atividades recreativas, expressivas e produtivas] (LIMA; OKUMA; PASTORE, 2013, p. 244).

O conceito de atividades criou raízes no processo histórico do desenvolvimento da profissão no Brasil, sendo o constructo centralizador que alicerçou a teoria e a prática da profissão.

Inicialmente, acreditava-se no poder terapêutico das atividades, que o fazer tinha o potencial de trazer benefícios para os pacientes atendidos em Terapia Ocupacional e que, a partir de uma análise detalhada da atividade, seria possível indicar a atividade mais adequada para um paciente ou uma determinada população (LIMA; OKUMA; PASTORE, 2013).

Porém, em 1990, é publicado o texto $O$ mito da atividade terapêutica, de Beatriz Nascimento ${ }^{2}$, produzindo um marco nas concepçóes da Terapia Ocupacional brasileira.

Neste texto, a autora propunha-se a desmascarar - por trás da ligação fácil e ideológica entre atividade e terapeuticidade - as práticas nomeadas de terapêuticas, que serviriam para ocultar a violência nas instituiçôes de exclusão (LIMA; OKUMA; PASTORE, 2013, p. 245). 
Assim, verificou-se, através das publicaçōes e reflexôes de terapeutas ocupacionais brasileiros, tendência ao abandono da expressão atividade terapêutica. A literatura mostra que a ideia de que a atividade possibilita se atingirem determinados objetivos de saúde vai, gradualmente, sendo substituída pela noção de atividade humana.

A atividade passa a ser vista como elemento que promove o encontro e o diálogo entre o sujeito, seu grupo social, seu tempo histórico, sua tradição cultural (LIMA; OKUMA; PASTORE, 2013, p. 246).

O CETO (Centro de Estudos em Terapia Ocupacional), que tem se debruçado sobre estudos no campo do Método Dinâmico em Terapia Ocupacional, apresenta o termo 'atividades' como o paradigma fundador da profissão, um instrumento específico da Terapia Ocupacional, que cria espaço para a saúde e possibilita construçóes no cotidiano (BENETTON, 2008). As atividades tornam possíveis as relaçóes entre os diversos fazeres e entre as possibilidades e habilidades (MORAES, 2008).

Com atividades, podemos

[...] tratar, educar, ensinar, organizar, alterar o ambiente e incluir pessoas num sistema que lhes permita integraçóes e interaçóes (BENETTON, 2008, p. 29).

As atividades,

[...] enquanto instrumento, têm diversos objetivos, dentre eles: a observaçáo, a informação, a análise, a educação, o tratamento, a composição de histórias e a inclusão social. Para isso as atividades são vindas e significadas na e pela relação triádica (MORAES, 2008, p. 31).

Mais recentemente, as atividades também têm sido consideradas enquanto uma possibilidade metodológica do terapeuta ocupacional na realização de suas pesquisas, segundo Silva (2013, p. 464). Assim, as atividades podem ser usadas no processo de análise e interpretação de dados de pesquisa, "[...] possibilitando a consideração de forma mais apropriada dos sujeitos, seus contextos, suas expressóes, incorporadas às demandas da pesquisa”.

Dessa forma, o termo de maior evidência na literatura brasileira é o termo atividade e

[...] diferentes formas de conceber e atuar com as atividades convivem, no contemporâneo, nas mais diversas práticas em TO, e termos como ocupação, fazer e ação coexistem na literatura com o termo atividade (LIMA; OKUMA; PASTORE, 2011, p. 69).

\subsection{O uso do termo ocupação na literatura nacional}

Segundo Lima, Okuma e Pastore (2013), poucos artigos na literatura brasileira utilizam o termo ocupação e, quando o termo é utilizado, este aparece conjuntamente com os termos atividades e ação, sem que se construa uma distinção entre eles.

Existem autores que utilizam o termo ocupação para se referir a um fazer sem significado, um fazer descontextualizado que não faz sentido na história do sujeito. Benetton (2008, p. 28), por exemplo, afirma que não devemos dar aos pacientes "[...] meras ocupaçóes para preencher o tempo ou ganhar migalhas e, sobretudo, no sentido de passar o tempo", e relaciona o termo ocupação ao paradigma médico, como um fazer para afastar a morbidade.

Neste sentido, é possível pensar na hipótese de que parte da Terapia Ocupacional brasileira realiza associaçóes entre o conceito de ocupação e um fazer sem significado, utilizado dentro do paradigma médico e institucional para afastar sintomas e organizar o tempo.

Alguns autores usam o termo ocupação intercambiavelmente com atividade e outros associam o termo a papéis ocupacionais produtivos. Porém,

[...] a ocupação também é determinada tendo como referência autores de língua inglesa, na qual o termo tem outros significados, no interior de modelos norte-americano ou canadense de Terapia Ocupacional (LIMA; OKUMA; PASTORE, 2013, p. 249).

Assim, alguns autores brasileiros têm começado a usar o termo ocupação, como descrito na literatura anglofônica, para fundamentar suas pesquisas.

\subsection{O termo ocupação na literatura publicada em língua inglesa}

A ocupação é um conceito básico para Terapia Ocupacional dos países de língua inglesa e sua relação com a saúde tem sido adotada como um elemento central na profissão, na literatura de língua inglesa.

De acordo com Bauerschmidt e Nelson (2011) e Bauerschmidt (2007), Kilhofner descreve uma sucessão histórica de três paradigmas que marcaram a Terapia Ocupacional. O primeiro paradigma, o paradigma da ocupação, começou no início do século XX. Porém, uma mudança nas ideias no campo da 
medicina, no final da década de 1940, causou uma crise na Terapia Ocupacional, que levou ao segundo paradigma, o paradigma mecanicista. Em vez de focar nos padróes ocupacionais, os Terapeutas Ocupacionais procuravam reabilitar seus pacientes, frequentemente com a ajuda de tecnologia assistida. Porém, conforme indicado por Bauerschmidt e Nelson (2011) e Bauerschmidt (2007), nos anos 1970, a inadequação deste modelo, que substitui as ideias holísticas dos fundadores da profissão por ideias reducionistas, criou uma nova crise, que levou ao retorno do compromisso com o conceito de ocupação e seus benefícios terapêuticos.

Bauerschmidt e Nelson (2011), em sua pesquisa de revisão de literatura, encontraram que o termo ocupação parece dominante nos anos 1920, mas parece diminuir de frequência nos anos 1940, 1950 e 1960. O uso dos termos ocupação e atividade, especialmente ocupação, reaparecem em 2000. Esta informação, de uma forma geral, oferece suporte para a teoria de Kielhofner (BAUERSCHMIDT; NELSON, 2011).

Em 1990, Yerxa e colegas introduziram a ciência ocupacional focando no conceito de ocupação, relacionado com o que as pessoas fazem (MÜLLERSDORF; IVARSSON, 2008). Com o advento da ciência ocupacional, se estabelece o zelo acadêmico pelo conceito de ocupação, enquanto o conceito de atividade passa a receber pouca atenção (PIERCE, 2003).

A compreensão da ocupação humana e seus condicionantes sociais, econômicos, culturais políticos etc., como procuramos mostrar, é o principal objetivo da recém-criada ciência ocupacional (MAGALHÂES, 2013, p. 261).

Na literatura anglófona em Terapia Ocupacional, o termo ocupação é associado a um fazer com significado, uma ação complexa, inerente a todo ser humano.

A reivindicação de uma fatia do mercado pela profissão é sustentada pela definição de como ocupação e atividade dão sentido à vida humana, e como possuem poder terapêutico para a recuperação (PIERCE, 2003, p. 14).

A ocupação é uma necessidade básica humana, que oferece significado para a vida. A ocupação é caracterizada por como ela é desempenhada, podendo acalmar ou acelerar o indivíduo. A ocupação não é algo normativo, mas depende da experiência subjetiva, é possível por meio de movimentos, funçôes e habilidades. Os resultados da ocupação podem melhorar a autoconfiança da pessoa (IVARSSON; MÜLLERSDORF, 2009).

Reed, Hocking e Smythe (2013) destacam que a ocupação não é algo que surge apenas do indivíduo, mas deve ser compreendida na totalidade complexa da pessoa em seu ambiente. Neste sentido, o significado da ocupação vai além de um significado individual.

Uma categoria central na reflexão sobre ocupação são as dimensôes porque, o que e o como, que estão relacionadas à ocupação. A dimensáo $o$ que inclui todas as ocupaçóes humanas, o contexto e os valores que influenciam a ocupação. Na dimensão porque, incluem-se os motivos e os resultados que são descritos como as razôes para desempenhar a ocupação. E a dimensão como oferece uma descrição da forma da ocupação. Na primeira dimensão, o fazer em um contexto inclui todas as ocupaçóes humanas, desde pequenas obrigaçóes até as ocupações que são realizadas na sociedade. O fazer é influenciado por valores, assim o que a sociedade e o indivíduo valorizam geram um grande impacto na escolha ocupacional (MÜLLERSDORF; IVARSSON, 2008).

Além disso, considera-se que a ocupação pode prevenir, desenvolver e proporcionar prazer e felicidade, e, portanto, influenciar a saúde e o bem-estar. A ocupação é considerada uma necessidade humana básica, de importância central para a saúde e o bem-estar (RUDMAN; DENNHARDT, 2008; IVARSSON; MÜLLERSDORF, 2009; CREEK; HUGHES, 2008; IVARSSON; MÜLLERSDORF, 2008).

Pierce (2003) declara que a ocupação é uma experiência individual, única e específica, construída pessoalmente e não repetível; é um acontecimento subjetivo, que acontece numa dimensão percebida de espaço, tempo e condiçóes sociais e culturais determinadas.

"As ocupaçôes têm um dia, uma hora, uma duração, um ritmo e uma sequência que não irão se repetir no fluir do tempo" (PIERCE, 2003, p. 17). Para a autora, pelo fato de as pessoas e os contextos sociais se transformarem constantemente, cada vez que realizamos uma ocupação temos uma experiência diferente; assim, cada ocupação é única.

Além disso, os artigos fazem referência à identidade ocupacional como um aspecto importante da ocupação. A identidade ocupacional é composta de múltiplas características, como as coisas que os indivíduos se consideram satisfeitos de fazer, seus papéis sociais e suas percepçóes do que o ambiente espera que eles façam. O início de uma incapacidade pode criar uma desconexão entre a identidade ocupacional e a competência, sendo necessário reformular as 
percepçóes do sujeito sobre si mesmo, para criar uma visão do futuro como algo possível (RUDMAN; DENNHARDT, 2008).

A identidade ocupacional é a expressão de vários aspectos da natureza humana em interação com o contexto, desenvolvida ao longo do curso da vida do indivíduo por meio de várias ocupaçôes. Ela é um meio crucial, a partir do qual as pessoas alcançam significado e propósito na vida (RUDMAN; DENNHARDT, 2008).

Reed, Hocking e Smythe (2013) acrescentam que as concepçóes atuais sobre a ocupação consideram a mesma central para a competência e a identidade do sujeito, o que influencia como as pessoas usam o tempo e tomam decisóes. Além disso, as ocupaçóes implicam em um senso de ação intencional e com propósito, e precisam ser referendadas pelo grupo social e cultural do sujeito.

Outro enfoque observado em alguns estudos refere-se ao fato de que a ocupação também pode ser utilizada na clínica, na atenção aos sujeitos atendidos pelos terapeutas ocupacionais (MAGALHÁES, 2013; LARSON, 2004), como tem ocorrido desde o início da profissão. Para Magalhães (2013, p. 261),

[...] os terapeutas ocupacionais têm diante de si a extraordinária tarefa de maximizar as possibilidades ocupacionais de indivíduos e grupos com os quais trabalham, a partir do reconhecimento do enorme potencial da ocupação criativa, significativa e transformadora.

Larson (2004) argumenta que o engajamento ocupacional pode ser considerado como um investimento emocional e um envolvimento cognitivo. O estímulo da complexidade e a densidade da experiência têm uma relação com as habilidades do sujeito em alcançar as demandas da tarefa. Se um cliente percebe uma ocupação como desinteressante, mudanças no envolvimento cognitivo ou emocional podem produzir uma experiência mais agradável. Se uma ocupação é vivenciada como demasiadamente desafiadora, o Terapeuta Ocupacional pode redesenhar a ocupação reduzindo sua complexidade e aumentando as habilidades do cliente. É importante criar um nível de desafio certo para o cliente. Essas mudanças têm um impacto na percepçâo da temporalidade e na experiência da ocupação.

Também é fundamental para a pesquisa se ter uma clara compreensão do termo ocupação. $\mathrm{Na}$ Suécia, por exemplo, tem sido discutido qual termo expressa melhor o conceito de ocupação usado em inglês e não se encontrou consenso em como traduzir 'ocupaçáa' do inglês para o sueco. Em sueco, o termo mais frequentemente usado, com o sentido dado a ocupação, em inglês, é atividade. A palavra atividade é o melhor termo usado em sueco na comparação do conceito, em inglês, de ocupação (IVARSSON; MÜLLERSDORF, 2008).

Os significados dados ao termo ocupação são complexos e variam entre os diferentes países e nos distintos modelos de Terapia Ocupacional. Dessa forma, aponta-se a importância de estudos futuros para o aprofundamento e o esclarecimento destas diferenças e significados.

\subsection{O termo atividade na literatura publicada em língua inglesa}

$\mathrm{Na}$ literatura de língua inglesa, o termo atividade frequentemente é desvalorizado, havendo, muitas vezes, uma relação hierárquica com o termo ocupação, que é priorizado na terminologia da profissão (MAGALHÃES, 2013; CREEK; HUGHES, 2008).

A expressão atividade tem sido frequentemente evitada ou secundarizada nos documentos de língua inglesa (MAGALHÃES, 2013). Nas últimas décadas, a palavra ocupação tem se tornado o principal domínio da profissão e tem se sugerido que o uso da palavra atividade, para se referir ao que as pessoas fazem, diminui e não representa a profissão (CREEK; HUGHES, 2008).

Porém, alguns autores, como Pierce, por exemplo, conceituam a atividade e náo retiram valor do uso do termo. A autora considera que a atividade é uma "[...] ideia que está na mente das pessoas e em sua linguagem cultural compartilhada", é uma classe geral de açôes humanas culturalmente definidas (PIERCE, 2003, p. 13).

Uma atividade é uma noção geral, irá nos informar sobre o que esperar em termos de sensações, valores culturais, contexto físico e tempo. O contexto cultural influencia os valores do que é ou não adequado se fazer e o que esperar de uma atividade (PIERCE, 2003).

Entretanto, os autores reconhecem a dificuldade na utilização dos termos desenvolvidos na língua inglesa, para outros países (MAGALHĀES, 2013).

Em muitos países, existe um movimento para fortalecer o paradigma da ocupação, que envolve se distanciar do modelo médico e olhar para a ocupação como uma base de conhecimento. Porém, surgem questóes sobre como estes conceitos se adaptam aos respectivos contextos culturais (RUDMAN; DENNHARDT, 2008). Mesmo em inglês, a expressão ocupação apresenta significados dúbios, que nem sempre podem ser traduzidos adequadamente 
para outros contextos linguísticos (MAGALHÃES, 2013; BAUERSCHMIDT; NELSON, 2011).

Assim, enquanto a maioria das teorias de grande influência na Terapia Ocupacional tem sido desenvolvida em áreas urbanas de países de língua inglesa, no mundo ocidental, estas teorias refletem, por definiçáo, o ponto de vista de uma minoria, pois a autora considera que a população dos países ocidentais representa uma minoria em relação à população mundial (HAMMELL, 2009).

\subsection{Discussões contemporâneas em torno do conceito de ocupação}

Estes princípios da ocupaçáo, conforme descritos anteriormente, não podem se tornar uma regra, algo que aprisiona o pensar no campo da Terapia Ocupacional. Tais princípios devem ser questionados e revistos frequentemente.

Por exemplo, a suposição de que todas as pessoas têm as condiçóes necessárias para melhorar a sua saúde é problemática, na medida em que revela sua origem em uma classe social economicamente confortável no mundo ocidental. Nem sempre as pessoas têm escolha, controle e oportunidade para exercer a sua vontade e transformar a sua vida. De fato, as suas ações podem fazer pouca ou nenhuma diferença nas circunstâncias da sua vida, que são limitadas por práticas discriminatórias, como o patriarcado e o sexismo, ou sobre fatores, como o fechamento de fábricas, os desastres naturais e as guerras, que estão além do controle das pessoas (HAMMELL, 2009).

A saúde depende de ter oportunidades para desenvolver suas capacidades e isto está relacionado a um ambiente que possibilite a ocupação. Porém, as populaçôes indígenas, os pobres, as mulheres, as pessoas com incapacidades físicas ou os imigrantes ilegais estão entre aqueles que não possuem as mesmas liberdades ou oportunidade de se engajar em ocupaçóes (HOCKING, 2013).

Molke e Rudman (2009) abordam que, como uma comunidade, os terapeutas ocupacionais devem refletir sobre suas tecnologias e crenças ocupacionais, e tentar identificar como elas trabalham para promover a realidade social, a moral e a ética individual. Muitas vezes, a ocupaçáo humana produtiva é idealizada e priorizada, assim como são priorizados os indivíduos que conseguem se engajar em ocupaçóes reconhecidas socialmente como relevantes. Este discurso náo dá atenção e tira a ênfase da grande variedade das ocupaçôes humanas, excluindo as ocupaçóes que tornam possíveis as relaçóes de interdependência.
Assim, será difícil alcançar uma definição universal de ocupação, porém é importante procurar conceituaçóes e perspectivas culturais que incluam a produção teórica do sul (MAGALHÂES, 2013).

\subsection{Aproximações e distanciamentos entre a literatura nacional $\mathrm{e}$ internacional}

Percebem-se as diferenças e semelhanças na utilização dos termos atividade e ocupação na literatura nacional e internacional.

Tanto o termo atividade como o termo ocupação se referem a um fazer que é capaz de influenciar os processos de saúde e doença, e o bem-estar do sujeito. Para se referir a um fazer significativo para o sujeito, que faça sentido em sua história pessoal e na sua vida, a literatura nacional utiliza o termo atividade e a literatura internacional utiliza o termo ocupação. O mesmo ocorre em relação ao fazer contextualizado, que está relacionado a determinado ambiente, cultura e contexto social. A atividade no Brasil também é considerada como algo individual, único na vida do sujeito, em afinidade ao que Pierce (2003) descreve sobre o conceito de ocupação.

A discussão dos termos atividade, na literatura nacional, e ocupação, na literatura ocidental, de diferentes formas, também traz questionamentos sobre como estes conceitos e como a prática da Terapia Ocupacional podem servir e fortalecer o sistema capitalista e suas instituiçóes. A literatura internacional questiona o conceito de ocupação que supervaloriza o trabalho e coloca o bem-estar como uma opçáo do sujeito - sem se questionar que os indivíduos nem sempre tem opções - e a literatura nacional questiona o conceito de atividade que, em muitas instituiçóes, serve para silenciar os sujeitos e mantê-los em uma situação de exclusão (LIMA; OKUMA; PASTORE, 2013; HAMMEL, 2009; HOCKING, 2013; MOLKE; RUDMAN, 2009).

Porém, essas aproximaçôes entre os conceitos não significam que o termo ocupação pode ser traduzido como atividade no Brasil, como ocorreu na Suécia, já que estes termos apresentam uma construção histórica e significados diferentes nos contextos nacional e internacional.

O termo ocupação se apresenta de forma ampla na literatura internacional, abarcando reflexōes pouco estudadas no Brasil e que pouco influenciam o conceito de atividade, como a concepção sobre identidade ocupacional, as reflexóes sobre temporalidade da ocupação ou sobre criar o nível de desafio apropriado para cada sujeito. 
$\mathrm{Na}$ literatura de língua inglesa, o termo ocupação esta atrelado ao potencial transformador na vida do indivíduo devido à potencialidade e ao significado do fazer para o sujeito; porém, na literatura nacional, o potencial transformador, relacionado ao conceito de atividade, além de ocorrer na vida e no contexto social do sujeito, também se apresenta na relaçáo terapêutica, no fazer em processo terapêutico ocupacional.

Assim, percebe-se que os conceitos de atividade e ocupação apresentam similaridades e diferenças, construídas em processos históricos distintos nos diversos países.

\section{Conclusão}

Compreende-se que este estudo contemplou o seu objetivo de colaborar para a compreensáo da definição e do uso dos conceitos de atividade e ocupação na Terapia Ocupacional, na literatura de língua inglesa e nacional. Estas diferenças e similaridades encontradas na literatura causam um impacto na prática profissional, encontrando-se a literatura de língua inglesa focada na ocupaçáo em si e a literatura nacional focada no processo desenvolvido na atenção ao sujeito. Porém, nota-se, como uma referência comum aos terapeutas ocupacionais, a preocupação em compreender a pessoa atendida em terapia ocupacional como um sujeito histórico, inserido em uma determinada cultura e vivenciando limitaçôes ou oportunidades sociais.

Percebe-se, como uma limitação deste estudo, a revisão de literatura dos últimos dez anos, já que estes conceitos têm sido estudados desde o início da profissão e muito foi produzido no último século. Além disso, a literatura nacional tem uma produçáo importante publicada em livros ou artigos de reflexão, por exemplo, que não foram incluídos para análise no presente artigo; são estudos que poderiam trazer contribuiçóes importantes sobre o conceito de atividade, que ficaram ausentes nesta discussão. Desta forma, indica-se a necessidade de pesquisas, com outras metodologias, que possibilitem a inclusão destes estudos e, de outros, que possam estar disponíveis em outras bases de dados que não foram aqui focalizadas.

A conceituação sobre os termos ocupação e atividade promove um processo dinâmico de transformação e está continuamente em desenvolvimento; dessa forma, serão necessárias maiores reflexôes e mais pesquisas sobre o assunto para aprofundar o conhecimento sobre o tema. Nesse contexto, o presente artigo não pretende trazer definiçôes acabadas sobre os termos, mas contribuir para o processo de reflexão e apreensáo do uso dos termos no contexto nacional e internacional. Espera-se, com este artigo, dar um passo, na longa jornada de refletir, conceituar e utilizar estes termos pela profissão, e que outras pesquisas possam continuar esta caminhada.

\section{Referências}

BAUERSCHMIDT, B. The terms activity and occupation over the history of occupational therapy official publications. Digital Repository, Toledo, v. 1, p. 1-21, 2007. Disponível em: <http://utdr.utoledo.edu/graduate-projects/147>. Acesso em: 17 nov. 2014.

BAUERSCHMIDT, B.; NELSON, D. L. The terms occupation and activity over the history of official occupational therapy. American Journal of Occupational Therapy, Rockville, v. 65, n. 3, p. 338-345, 2011.

BENETTON, J. Atividades: tudo o que você quis saber e ninguém respondeu. Revista do Centro de Estudos de Terapia Ocupacional, São Paulo, v. 11, n. 11, p. 26-29, 2008.

CREEK, J.; HUGHES, A. Occupation and health: a review of selected literature. British Journal of Occupational Therapy, Londres, v. 71, n. 11, p. 456-468, 2008.

GALVÃO, C. M.; SAWADA, N. O.; TREVIZAN, M. A. Revisão sistemática: recurso que proporciona a incorporação das evidências na prática da enfermagem. Revista Latino Americana de Enfermagem, Ribeirão Preto, v. 12, n. 3, p. 549-556, 2004.

GOLLEDGE, J. Distinguishing between occupation, purposeful activity and activity part 1: review and explanation. British Journal of Occupational Therapy, Londres, v. 61, n. 3, p. 100-105, 1998.

GRANT, J. M.; BOOTH, A. A typology of review: an analysis of 14 review types and associated methods. Health Information and Libraries Journal, Londres, v. 26, n. 2, p. 91-108, 2009.

HAMMELL, K. W. Sacred texts: a skeptical exploration of the assumptions underpinning theories of occupation. Canadian Journal of Occupational Therapy, Ottawa, v. 76, n. 1, p. 6-12, 2009.

HOCKING, C. Occupation for public health. New Zealand Journal of Occupational Therapy, Wellington, v. 60, n. 1, p. 33-37, 2013.

IVARSSON, A.; MÜLLERSDORF, M. An Integrative review combined with a semantic review to explore the meaning of Swedish terms compatible with occupation, activity, doing and task. Scandinavian Journal of Occupational Therapy, Stockholm, v. 15, n. 1, p. 52-63, 2008.

IVARSSON, A.; MÜLLERSDORF, M. Occupation as described by novice occupational therapy students in Sweden: a follow up study. Scandinavian Journal of Occupational Therapy, Stockholm, v. 16, n. 1, p. 57-64, 2009. 
KANTARTZIS, S.; MOLINEUX, M. The influence of western society's construction of health daily life on the conceptualization of occupation. Journal of Occupational Science, Sidney, v. 18, n. 1, p. 62-80, 2011.

LARSON, E. A. Time of our lives: the experience of temporality in occupation. Canadian Journal of Occupational Therapy, Ottawa, v. 71, n. 1, p. 24-35, 2004.

LIMA, E. M. F. A.; OKUMA, D. G.; PASTORE, M. N. Atividades, ação, fazer e ocupação: a discussão dos termos na Terapia Ocupacional brasileira. Cadernos de Terapia Ocupacional da UFSCar, Sáo Carlos, v. 21, n. 2, p. 243-254, 2013.

LIMA, E. M. F. A.; PASTORE, M. N.; OKUMA, D. G. Atividades no campo da Terapia Ocupacional: mapeamento da produçáo científica dos terapeutas ocupacionais brasileiros de 1990 a 2008. Revista de Terapia Ocupacional da USP, São Paulo, v. 22, n. 1, p. 68-75, 2011.

MAGALHÃES, L. Ocupação e atividade: tendências e tensóes conceituais na literatura anglófona da terapia ocupacional e da ciência ocupacional. Cadernos de Terapia Ocupacional da UFSCar, São Carlos, v. 21, n. 2, p. 253-263, 2013.

MOLKE, D. K.; RUDMAN, D. L. Governing the majority word? Critical reflections in the role of occupation technology in international contexts. Australian Occupational Therapy Journal, Richmond, v. 56, n. 4, p. 239-248, 2009.

MORAES, G. C. Atividades: uma compreensão dentro da relação triádica. Revista do Centro de Estudos de Terapia Ocupacional, São Paulo, v. 11, n. 11, p. 30-35, 2008.
MÜLLERSDORF, M.; IVARSSON, A. Occupation as described by novice occupational therapy students in Sweden: the first step in a theory generative process grounded in empirical data. Scandinavian Journal of Occupational Therapy, Stockholm, v. 15, n. 1, p. 34-42, 2008.

NASCIMENTO, B. A. O mito da atividade terapêutica. Revista de Terapia Ocupacional da Universidade de São Paulo, São Paulo, v.1, n. 1, p. 17-21, 1990.

NELSON, D. L.; JONSSON, H. Occupational terms across languages and countries. Journal of Occupational Science, Adelaide, v. 6, n. 1, p. 42-47, 1999.

PIERCE, D. Desembaraçando ocupação e atividade. Revista do Centro de Estudos de Terapia Ocupacional, São Paulo, v. 8, n. 11, p. 13-26, 2003.

REED, K.; HOCKING, C.; SMYTHE, L. The meaning of occupation: historical and contemporary connections between health and occupation. New Zealand Journal of Occupational Therapy, Wellington, v. 60, n. 1, p. 38-42, 2013.

RUDMAN, D. L.; DENNHARDT, S. Shaping knowledge regarding occupation: examining the cultural underpinnings of the evolving concept of occupational identity. Australian Occupational Therapy Journal, Richmond, v. 55, n. 3, p. 153-162, 2008.

SILVA, C. R. As atividades como recurso para a pesquisa. Cadernos de Terapia Ocupacional da UFSCar, São Carlos, v. 21, n. 3, p. 461-470, 2013.

\section{Contribuição dos Autores}

Mariana Moraes Salles realizou a elaboração do projeto de pesquisa, a coleta e análise de dados, a discussão e a redação do artigo. Thelma Simóes Matsukura participou de todas as etapas do estudo e realizou revisão crítica do texto. Todos os autores aprovaram a versão final do texto.

\section{Fonte de Financiamento}

FAPESP - Fundação de Amparo a Pesquisa do Estado de São Paulo - Processo no 2011/23424-5.

\section{Notas}

${ }^{1}$ O presente artigo faz parte da pesquisa de pós-doutorado de título "Vida cotidiana e saúde mental: contextualizando as ocupações e o uso do tempo de usuários de centros de atenção psicossocial”, desenvolvido no Programa de Pós-Graduação em Terapia Ocupacional, Departamento de Terapia Ocupacional, Universidade Federal de São Carlos.

${ }^{2}$ Nascimento (1990). 